\title{
A case with probable herpes simplex encephalitis characterized by specific emotional and behavioral disorders and Gogi (word-meaning) aphasia-like syndrome with neologism and neologistic kanji processing
}

\author{
I. Jibiki and N. Yamaguchi \\ Department of Neuropsychiatry, Kanazawa University School of Medicine, \\ 13-1 Takaramachi, Kanazawa, Ishikawa Prefecture, 920 Japan
}

Correspondence to: I. Jibiki at above address

\begin{abstract}
A right-handed male patient with probable herpes simplex encephalitis is presented because of the rarity of the clinicial picture. Brain X-ray CT scans showed lesions located in the bilateral fronto-temporal regions primarily involving the left lower temporal lobe. The clinical picture following the acute phase of the disease was characterized by specific emotional and behavioral disorders, i.e. oral tendency, hyperactivity, thoughtless talkativeness, random speech and exhilaration, which were partly compatible with the Klüver-Bucy syndrome. Furthermore, this case was characterized by Gogi (word-meaning) aphasia-like transcortical sensory aphasia and neologism produced saliently when naming objects and peculiar neologistic kanji processing in writing to dictation and oral reading. Both the neologism and neologistic kanji processing varied in quantity in parallel with the specific emotional and behavioral disorders. The relationships of these clinical features to lesional sites demonstrated by $\mathrm{X}$-ray CT are discussed.
\end{abstract}

Keywords: Aphasia - Emotional and Behavioral Disorders - Herpes simplex encephalitis - Klüver-Bucy syndrome Neologism

\section{INTRODUCTION}

The Japanese written language consists of two kinds of characters, kana as phonetic symbols for syllables or mora-sized units and kanji (Chinese characters) as nonphonetic logographic symbols which are semantic in nature. Kanji characters have two types of phonetic forms or reading, i.e. on-reading (Sino-Japanese reading derived from the Chinese pronunciation of the characters) and kun-reading (a native Japanese reading), each expressing a specific meaning. From ancient times, the proper use of these readings has been established according to the semantic expression in kanji words which consist of one or more kanji characters. Furthermore, different kanji characters occasionally have identical on- or kun-readings. Therefore, in writing to dictation and oral reading, one must first grasp the semantic content of the dictated words and written kanji words in order to find the correct orthographic and phonological forms of the kanji words, respectively.

Gogi (literally, "word-meaning") aphasia first proposed by Imura (1943) and thereafter extended by Sasanuma and Monoi (1975) is a unique aphasic syndrome exhibited only in Japanese patients. One of the defining features of Gogi aphasia is a marked dissociation between kanji and kana processing, i.e. selective impairment of kanji processing in writing or oral reading and preservation of kana processing (Imura, 1943; Sasanuma and Monoi, 1975). The impairment of kanji processing is often characterized by a sort of neologistic kanji processing, i.e. "phonetic use of kanji in writing" and "confusion between on- and kunreadings of kanji in oral reading". Other salient features are disturbances in comprehending spoken and written language, difficulty in retrieving content words, and fluent oral repetition. These features of Gogi aphasia can be explained by selective dysfunction in finding access to the semantic aspects of the lexicon (or word meaning) in the context of preservation of phonologic functions (Sasanuma and Monoi, 1975). At present, Gogi aphasia is regarded as a type of transcortical sensory aphasia on account of these features (Iwata, 1984).

In the present report, we describe a patient with sequelae of herpes simplex encephalitis characterized by specific emotional and behavioral aberrations, Gogi apha- 
sia-like transcortional sensory aphasia, and neologism and neologistic kanji processing. However, the neologistic kanji processing differed from the above-mentioned characteristic of Gogi aphasia. We focus on the relationships of these clinical features to lesional sites demonstrated by X-ray CT. These symptoms have rarely been described in the literature.

\section{CASE REPORT}

The patient was a 34-year-old, right-handed man with an earnest, methodical and strict personality. He lived in Fukui with his wife, mother and two daughters after graduating from the faculty of Science of Kanazawa University, working as an engineer in a dye house. There was no evidence of either mental or remarkable physical illness in his medical and family histories. On August 10, 1980, he developed fever, malaise and headache. Three days later he was admitted to Fukui Prefectural Hospital, in stupor. During the subsequent 10 days, he remained comatose and developed daily fever in the range of $37.0-39.0^{\circ} \mathrm{C}$ and nuchal rigidity. $\mathrm{He}$ also had generalized convulsions several times during a 2-day period. Lumbar puncture performed on August 15 showed clear cerebrospinal fluid (CSF) with 304 lymphocytes $/ \mathrm{mm}^{3}$, and protein and glucose of, respectively, 73 and $90 \mathrm{mg} / \mathrm{dl}$. Moreover, a routine blood examination on the same day revealed 12,000 white blood cells. The antibody titration test for herpes simplex virus was negative in both the serum and CSF taken on August 15 but revealed a positive titer of 1:64 in the serum on August 29.

A diagnosis of encephalitis was made and he was given an intravenous drip containing antibiotics, steroids, human immunoglobulin and antimetabolic agent, Cytarabine. He started to awake from the coma 10 days after the admission and thereafter made a gradual recovery. About 2 months after the admission, he appeared alert but revealed severe mental deficits, i.e. dementia, amnesia, disorientation and aphasia. On November 24, 1980, he was transferred to the department of Neuropsychiatry of Kanazawa University Hospital for a more detailed examination of these deficits. He remained in our hospital for 375 days until his discharge on December 3, 1981. The clinical manifestations observed during this period are described below.

\section{General mental findings}

From the beginning of his admission to our hospital until the end of January, 1981, he appeared apathetic and dull. He lay in bed and was reticent even in the daytime because of a lack of spontaneity. He was disoriented with respect to time and place. His impairment of memory was so severe that he could not recall his own birth date, age, occupation or career. Moreover, he often named his family, e.g. he called his mother by his wife's name, although he could recognize them correctly. In addition, he sometimes showed incontinence of urine and faeces.

Subsequently, he gradually became more active and then, hyperactive, hilarious and talkative for the period extending from the middle of February until the end of May 1981. During this period, his disorientation for time and place gradually improved. He distractedly wandered about the ward and thoughtlessly spoke to everybody with a set phrase, i.e. "antadaisukiya" (Japanese for "I like you"). Furthermore, he often showed random speech (Vorbeireden) when he could not recall what he was asked, and had a tendency to put toys, pencils and lighters into his mouth.

By the beginning of June, the above-mentioned specific emotional and behavioral disorders, i.e. oral tendency, hyperactivity, thoughtless talkativeness, random speech and exhilaration had decreased. Both the oral tendency and random speech disappeared during the period extending from June until discharge from our hospital, although the hyperactivity, talkativeness and exhilaration persisted to some extent. During this period, he was euphoric, childish and distractible with inappropriate jocularity, and manifested a personality change. His orientation for time and place returned to normal with the disappearance of the urinary and fecal incontinence. However, both his amnesia and dementia remained so severe that he could only fragmentarily recall even his own occupation and career, although he became able to recall his birth date, age and family members' names. Furthermore, he showed a severe disturbance of recent memory. He revealed a tendency to neglect thinking (Denkfaulheit), answering "wakaran" (Japanese for "I don't know") as soon as he could not recall what he was asked. A WAIS intelligence test administered to him on November 16, 1981 showed scores of 50, 60 and 44 for verbal, performance and total IQ, respectively. Furthermore, on the Benton visual memory test administered at almost the same time, he made 15 errors performing only three of the total of 10 subjects correctly.

\section{Neuropsychological findings}

Neuropsychological examinations were started in the middle of February 1981, at which time his general mental state was sufficiently improved to enable him to cooperate.

1. Auditory comprehension. He performed poorly on most comprehension tasks throughout his admission in our hospital. In pointing to pictures of familiar objects when these names were spoken by examiners, he made 21 and 16 unrelated errors on 38 items (e.g. "glasses" for "key") on identical tests conducted on September 3rd and December 1st, 1981, respectively, showing slight improvement on the latter corresponding to 2 days before 
his discharge from out hospital. Similar results were obtained with colors and parts of the body. He did even worse on sentence comprehension, making 6 errors in performing 10 spoken commands.

2. Speech. He could speak fluently without agrammatism or dysprosody. However, his speech was characterized by "neologism". The neologism appeared as he began to exhibit the above-mentioned specific emotional and behavioral disorders, and was most prominent when performing the object naming test.

Naming. In naming familiar objects presented by pictures, he missed all 10 items in the tasks performed repeatedly in the period extending from the middle of February until July 15 th 1981 . He compensated for this failure with nonsense or random neologisms (e.g. "miyabun" and "kitsuatsu" for "douka" and "tokei", the Japanese words for coin and watch, respectively). His neologism had no phonemical or semantical relation with the correct target word in any item. For the period extending from the beginning of March until the end of May 1981, the neologism was so pronounced that he compensated for every missed item with it. From June onwards his neologisms decreased in parallel with a decrease in the specific emotional and behavioral disorders. On the same naming test, performed on November 18th, he missed 8 of 10 items, showing a slight improvement. Verbal paraphasia as unrelated substitutions (e.g. "shinbun", which signifies newspaper, for "megane" signifying glasses) or a lack of response comprised the greater part of the errors with only an occasional neologism being present.

Repetition. He performed remarkably well on the task of oral repetition, in which language consisted of monosyllable or polysyllable, meaningful or meaningless words, and three- to five-words sentences, although he did not often understand their semantic content.

In addition, in explaining situational pictures, he produced sentences that were grammatically well formed but meaningless because of neologism and verbal paraphasia. However, in ordinary conversation, he did not show neologism or paraphasia sufficiently marked to render his speech incoherent (i.e. so-called "jargon") at any time during the admission period.

3. Reading. In oral reading, he revealed a striking dissociation of kanji and kana processing. When he was asked to read words aloud, he could read almost all kana words correctly, although his comprehension of their meaning was poor. In contrast, he failed to read kanji words aloud correctly, even simple ones used commonly, with poor comprehension of their meaning. He also failed to read sentences in which kanji and kana were used in combination, because of his specific inability to read the former. Such a dissociation was consistently observed throughout the admission period. In the period extending from the middle of February until the end of May 1981, he failed to read 28 of 30 kanji words correctly and compensated for almost all of the missed items with neologistic oral readings. The neologistic oral readings appeared to be produced nonsensically or randomly in common with the above-mentioned neologism in object naming tasks. Furthermore, the neologistic oral readings were unrelated to the on- and kun-reading or semantic content of the kanji word in each item (Fig. 1). Subsequently, the neologistic oral reading was reduced in parallel with a decrease in the neologism. On the identical task performed on September 17th, 1981, he missed 24 of the 30 items, showing slight improvement, and compensated for 17 of the missed 24 items with neologistic oral readings. He showed no responses to the remaining missed items. The so-called "confusion between on- and kun-reading of kanji" characteristic of Gogi aphasia was not observed at any time during his admission.

4. Writing. Also in writing to dictation, he revealed a striking dissociation of kanji and kana processing. He could write dictated words or sentences with kana easily and correctly, although, with poor comprehension of the semantic content of what he was writing. In contrast, his writing of kanji deteriorated drastically. His inability to write kanji was more pronounced than that in reading them, because he failed to write even simple kanji words which he could read aloud. Such a failure was also consistently observed throughout his admission period. In the period extending from the middle of February until the end of May 1981, he failed to write all of 30 dictated words with kanji correctly and compensated for almost all of the missed items with neologistic writings of kanji or kanji-like characters. The kanji-like characters consisted of random compositions or

$$
\begin{array}{ll}
\text { A 時 計 } & \text { B 眼 鏡 } \\
\begin{array}{l}
\text { tokei } \rightarrow \text { kotsuketsu } \\
\text { (watch) }
\end{array} & \begin{array}{l}
\text { megane } \rightarrow \text { mōsatsu } \\
\text { (glasses) }
\end{array} \\
C \text { 天 気 } & \text { D 魚 } \\
\begin{array}{l}
\text { tenki } \rightarrow \text { senkin } \\
\text { (weather) }
\end{array} & \begin{array}{l}
\text { sakana } \rightarrow \text { shinkeibai } \\
\text { (fish) }
\end{array}
\end{array}
$$

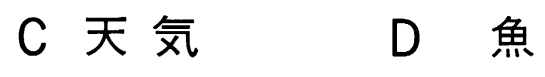

FIG. 1. Neologistic oral reading of Kanji words. The neologistic oral reading was unrelated to the phonetic forms inherent to each kanji character, i.e on- and kun-readings (e.g. in D, the term "sakana" is the kun-reading, and "gyo" the on-reading). 


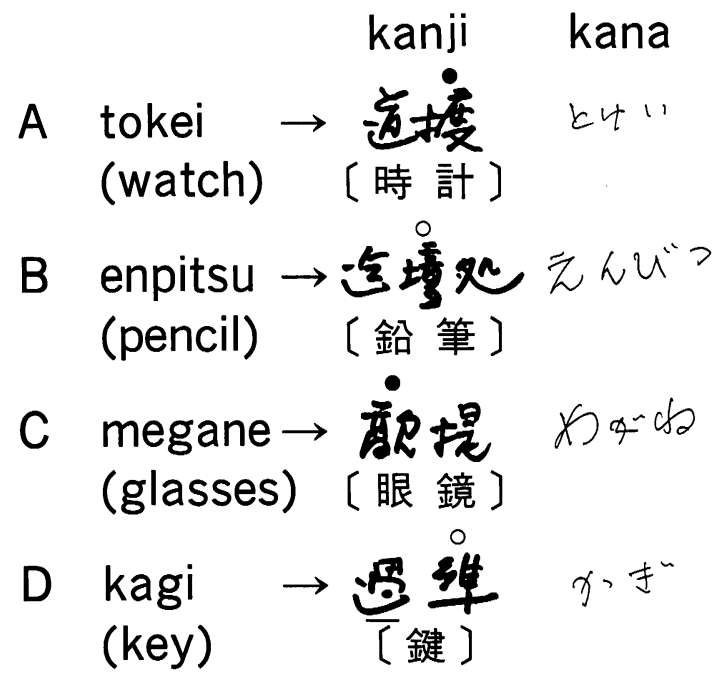

FIG. 2. Neologistic kanji or kanji-like words in writing to dictation. Words on the left side show the words spoken by examiners. In writing kanji, the patient wrote two or three neologistic character compounds, in which established kanji characters or kanji-like characters were meaninglessly or randomly spelled. The kanji-like characters consisted of random composition $(\bullet)$ or modification $(\bigcirc)$ of established kanji characters and their right- and left-hand radicals. The neologistic writing was morphologically irrelevant to the correct target kanji characters ([ ]). Furthermore, the neologistic writing was phonetically irrelevant to the spoken words, although the "phonetic use of kanji" peculiar to Gogi aphasia was rarely observed (the kanji character underlined in $D$ can be pronounced "ka" in on-reading, corresponding to the first syllable in the dicated word). On the other hand, the patient could write kana correctly and easily.

modifications of established kanji characters and their right- and left-hand radicals. The neologistic writing mainly consisted of two- or three-character words, in which the kanji-like characters or established kanji characters were meaninglessly or randomly spelled. The kanji or kanji-like characters in the neologistic writing were orthographically irrelevant to the kanji characters as the correct target in each item. Furthermore, in most cases, the neologistic writing was phonologically or semantically irrelevant to the dictated word in each item, although the "phonetic use of kanji" peculiar to Gogi aphasia was rarely observed (Fig. 2). Thereafter, the neologistic writing, too, decreased in parallel with a reduction in the neologism and neologistic oral reading. In an identical task performed on November 11, 1981, he could write 6 of the identical 30 items using the correct kanji, showing improvement. He responded to the remaining missed items with neologistic writing or writing nothing, with the latter accounting for the greater part of the errors.

In addition, when he was asked to write a letter spontaneously, he wrote the greater part of the sentences with kana. On the other hand, he could transcribe kanji words easily and correctly, although he only poorly comprehended them.

5. Calculation. When he was asked to mentally calculate numerical formulas with addition, substraction, multiplication and division spoken by examiners, he could solve correctly only the formulas consisting of single digits in March, 1981, and those consisting of one and two digits, although only the simpler ones, in November. However, his ability to calculate was relatively good when answering in writing written formulas.

6. Other neuropsychological tests. In contrast to the severe impairment in language modalities described above, he revealed neither apraxia nor agnosia during the admission period.

His neuropsychological findings are summarized as follows. He showed an aphasia characterized by the impaired kanji processing and preserved kana processing in writing or oral reading, disturbances in comprehending spoken and written language, inability to name objects or things, and fluent speech or oral repetition. These features are compatible with those of Gogi aphasia. However, he showed little evidence of the so-called "phonetic use of kanji in writing" and "confusion between on- and kunreadings of kanji in oral reading" often observed in Gogi aphasia. Instead, he exhibited nonsense and random neologistic kanji processing in writing and oral reading, and neologism produced saliently when naming objects. These peculiar neologistic symptons varied in quantity in parallel with specific emotional and behavioral disorders in his general mental state, i.e. oral tendency, hyperactivity, thoughtless talkativeness, random speech and exhilaration.

\section{Neurological and laboratory findings}

Neurological examinations at the time of the admission showed only muscle weakness of the right leg with brisk right knee and ankle jerks. Because of this weakness, he walked with a slight limp. About 2 months after admission, this weakness had almost completely disappeared. The herpes simplex virus antibody titration test revealed a positive titer of 1:16 in both the serum and CSF obtained on the second day of admission, and thereafter, showed a normal titer of 1:4 in both fluids.

\section{EEG findings}

The basic EEG pattern showed 7-9 $\mathrm{Hz}$ activities of 50-70 $\mu \mathrm{V}$ in the earlier stage during his hospital stay and thereafter, continued to show faster activities of $10 \mathrm{~Hz}$ with less mixing of 7-8 $\mathrm{Hz}$ activities. Moreover, high voltage slow waves of 2-3 Hz localized in the bilateral frontal leads at times appeared. 


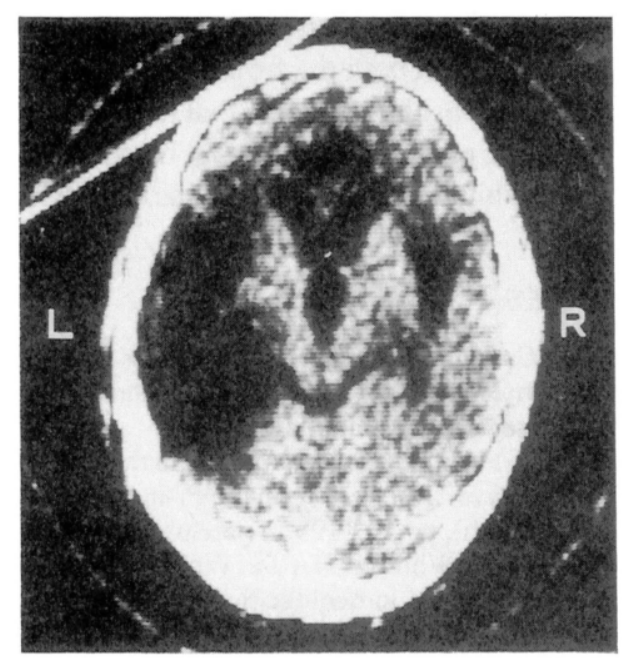

FIG. 3. Brain X-ray CT. A transeverse axial tomographic image at a height $25 \mathrm{~mm}$ above the orbitomeatal base line shows bilateral low density areas in the lower frontal and temporal lobes, with massive lesions in the left lower temporal lobe. R, right; L, left.

\section{Brain X-ray computed tomographic (CT) findings} Brain X-ray CT showed low density areas in the bilateral frontal and temporal lobes with massive lesions predominant in the left temporal lobe (Fig. 3). Both the frontal and temporal lesions were located primarily in the respective lower parts. These CT findings remained almost unchanged on repeated examinations in our hospital.

Follow-up of the clinical features. After discharge, reassessment of the clincial features was performed every 2 or 3 years. During the follow-up period about 10 years from discharge to the most recent examination, he showed no improvement in the overall symptoms with respect to general mental state or neuropsychological findings, rather exhibiting a slightly enhanced memory deficit, dementia and deterioration of personality associated with a slight and gradual enlargement of the bilateral frontotemporal lesions on CT. The aphasia continued to show the same profile, however, with additional paragraphic errors in kana processing.

\section{DISCUSSION}

The presumed diagnosis of this patient was herpes simplex encephalitis in view of the sudden onset of his illness with fever, headache and lethargy, and the laboratory data, i.e. leucocytosis, the pleocytosis in the CSF and the positive antibody titer for herpes simplex virus in the CSF and serum. His brain X-ray CT findings were compatible with those reported in herpes simplex encephalitis, namely low density areas in the unilateral or bilateral temporal lobes which occasionally extend to the frontal lobes (Enzmann et al., 1978; Davis et al., 1978; Kaufman et al., 1979; Dutt and Johnston, 1982; Damasio and Hoesen, 1985; Kennedy, 1988; Weisberg et al., 1988). Furthermore, the clinical features, such as coma, memory deficit, disorientation, convulsive seizure, focal neurological signs (muscle weakness of the right lower extremity), and personality change are recognized as common symptoms in herpes simplex encephalitis, based on the reports of Whitely (1982) and Shoji (1982) who collected clinical data from 113 and 142 cases, respectively. Also, his specific emotional and behavioral disorders, i.e. oral tendency, hyperactivity, thoughtless talkativeness, random speech and exhilaration, and subsequent specific personality change with euphoria, inappropriate jocularity and distractibility, are similar to the clinical features described in case reports of herpes simplex encephalitis or necrotizing encephalitis (Drachman and Adams, 1962; Gascon and Gilles, 1973). Especially, the former two symptoms are compatible with a part of the Klüver-Bucy syndrome, which is known to result from bilateral temporal lesions. It is also known that this syndrome is often observed in herpes simplex encephalitis (Shoji et al., 1979).

Aphasia or dysphasia is often observed in herpes simplex encephalitis (Whitley et al., 1982; Kennedy, 1988). However, few detailed reports about the aphasia found in herpes simplex encephalitis have appeared in the literature. To our knowledge, in the West, there are reports of cases with Wernicke's aphasia (Hier and Mohr, 1977), fluent sensory aphasia (possibly Wernicke's aphasia, Arlazoroff et al., 1984), amnestic anomia and selective impairment of specific semantic categories (Pietrini et al., 1988). In Japan, one case with total aphasia, anomic aphasia and pure word deafness has been reported (Ishige et al., 1990). Two cases with amnestic aphasia and one case with Gogi aphasia such as the present case have also been described in abstract form. Few detailed case reports describing herpes simplex encephalitis with Gogi aphasia peculiar to Japanese are available even in Japan. However, this apasia has been at times reported in cases with cerebrovascular diseases, progressive cerebral atrophy and encephalitis of unknown etiology. It has generally been regarded that the lesions responsible for Gogi aphasia are located in the second and third temporal lobes in the dominant hemisphere, often extending to the parietal region but sparing the Broca and Wernicke areas (Imura, 1943; Sasanuma and Monoi, 1975). Although the detailed anatomical identification of the frontal and temporal lesions from brain X-ray CT scans in the present case was difficult, the present finding that the massive lesion in the left temporal lobe was located primarily in the deeper regions, appears to be consistent with this general opinion. It seems that herpes simplex encephalitis possibly caused by transneural infection from the basis of the anterior and middle fossae (Davis and Johnson, 1979) selectively affects the basal or lower temporal lobes. Therefore, it is likely that the 
Gogi aphasia attributed to the lower temporal lesions is produced in herpes simplex encephalitis as in the present case, although various types of aphasia can be produced according to the extent of the lesions.

Case reports about herpes simplex encephalitis associated with neologism are extremely rare. To our knowledge, there is only the single case reported by Arlazoroff $e t$ al. (1984), who described neologism accompanying fluent sensory aphasia (possibly Wernicke's aphasia) and incomplete Klüver-Bucy syndrome with a left fronto-temporal abnormality on ${ }^{99 m} \mathrm{Tc}$ brain scan. Several papers about neologistic jargon have appeared in the literature (Kertesz and Benson, 1970; Buckingham, 1978; Brown, 1979; O'Connell, 1981; Hadano et al., 1984). It has been proposed that neologistic jargon may result from three types of underlying mechanisms, i.e. phonemic dysfunction as an extremely severe form of literal paraphasia (Kertesz and Benson, 1970), mixed dysfunction in the phonemic and semantic aspects of the lexicon (O'Connell, 1981), and compensation for anomia or word amnesia (Buckingham, 1978). The present case exhibited no phonemic dysfunction, showing fluent speech and correct oral repetition with no literal paraphasia. Therefore, the first hypothesis is considered untenable. We prefer to apply the third hypothesis for the neologism in the present case, since he showed marked anomia, i.e. inability to name objects or things. His neologistic kanji processing in writing and oral reading, too, may be explained by the compensation theory for the impaired kanji processing. In the present case, both the neologism and neologistic kanji processing varied in quantity in parallel with the specific emotional and behavioral disorders. In particular, the hyperactivity, talkativeness and exhilaration closely correlated with the neologistic symptoms, whereas the oral tendency and random speech disappeared in spite of the persistence of the neologistic symptoms. It is speculated that such specific emotional and behavioral disorders like a hypomanic state induce the highly elevated drive to compensate for the amnestic or impaired lingustic processing and the failure of self-control to inhibit such a drive. A part of the specific emotion and behavioral disorders may be attributed to the bilateral temporal lesions, because they are partly compatible with the Klüver-Bucy syndrome. Morever, the bilateral temporal lesions can also produce a hypomanic state in view of Hasegawa's report (1960) that this state was seen in a case with bilateral temporal lobectomy. However, in general, the frontal lobe and frontotemporal limbic system have long been regarded as sites responsible for emotional and disinhibited behavioral disorders (Poeck, 1969; Cummings, 1985). In particular, it is known that orbito-frontal lesions often produce a hypomanic state with euphoria, inappropriate jocularity and distractibility such as in the present case (Cummings, 1985). In view of these findings, the present specific emo- tional and behavioral disorders, especially the hypomanic state, may result from both the fronto-temporal and bilateral temporal lesions. It is possible that the neologism and neologistic kanji processing, too, may be correlated with more extensive bilateral lesions as well as the left temporal lesion.

\section{REFERENCES}

Arlazoroff A, Carpel CL, Zonis H, Goldenberg E and Zekler E (1984) Incomplete Klüver-Bucy syndrome and fluent aphasia. Brain and Language, 23, 300-306

Brown JW (1979) Language representation in the brain. In: Neurobiology of Social Communication in Primates (Eds H Steklis and M Raleigh), pp.133-195. Academic Press, New York.

Buckingham Jr HW, Whitaker HA and Whitaker H (1978) Alliteration and assonance in neologistic jargon aphasia. Cortex, 14, 365-380.

Cummings JL (1985) Clinical Neuropsychiatry. Grune \& Stratton, Orlando.

Damasio AR and Hoesen GWV (1985) The limbic system and the localization of herpes simplex encephalitis. Journal of Neurology, Neurosurgery and Psychiatry, 48, 297-301.

Davis JM, Davis KR, Kleinman GM, Kirchner HS and Taveras JM (1978) Computed tomography of herpes simplex encephalitis, with clinicopathological correlation. Radiology, 129, 409-417.

Davis LE and Johnson RT (1979) An explanation for the localization of herpes simplex encephalitis? Annual Neurology, 5, $2-5$.

Drachman DA and Adams RD (1962) Herpes simplex and acute inclusion-body encephalitis. Archives of Neurology, 7, 45-63.

Dutt MK and Johnston IDA (1982) Computed tomography and EEG in herpes simplex encephalitis: their value in diagonsis and prognosis. Archives of Neurology, 39, 99-102.

Enzmann RD, Ranson B, Norman D and Talberth E (1978) Computed tomography of herpes simplex encephalitis. Radiology, 129, 419-425.

Gascon GG and Gilles F (1973) Limbic dementia. Journal of Neurology, Neurosurgery and Psychiatry, 36, 421-430.

Hadano K, Hamanaka T, Ohigashi Y and Ohashi H (1984) On 5 cases of neurologistic jargonaphasia. Clinical Psychiatry (Tokyo), 26, 701-710.

Hasegawa T (1960) Mental changes following temporal lobectomy for epilepsy. Psychiatria et Neurologia Japonica, 62, 398-431.

Hier DB and Mohr JP (1977) Incongruous oral and written naming: evidence for a subdivision of the syndrome of Wernicke's aphasia. Brain and Language, 4, 115-126.

Imura T (1943) Aphasia: characteristic symptoms in Japanese. Psychiatria et Neurologia Japonica, 47, 196-218.

Ishige N, Hosoi Y and Fukaya H (1990) Three cases of herpes simplex encephalitis presented with various types of aphasia. IRYO, 44, 35-38.

Iwata M (1984) Kanji versus Kana: neuropsychological correlates of the Japanese writing system. Trends in Neurosciences, 7, 290-293.

Kaufman D, Zimmerman RD and Leeds NE (1979) Computed tomography in herpes simplex encephalitis. Neurology, 29, 1392-1396.

Kennedy PGE (1988) A retrospective analysis of forty-six cases of herpes simplex encephalitis seen in Glasgow between 1962 and 1985. Quarterly Journal of Medicine, 255, 533-540.

Kertesz A and Benson DF (1970) Neologistic jargon: a clinico- 
pathological study. Cortex, 6, 362-386.

O'Connell PF (1981) Neologistic jargon aphasia: a case report. Brain and Language, 12, 292-302.

Pietrini V, Nertempi P, Vaglia A, Revello MG, Pinna V and Ferro-Milone F (1988) Recovery from herpes simplex encephalitis: Selective impairment of specific semantic categories with neuroradiological correlation. Journal of Neurology, Neurosurgery and Psychiatry, 51, 1284-1293.

Poeck K (1969) Pathophysiology of emotional disorders associated with brain damage. In: Handbook of Clinical Neurology 3 (Eds PJ Vinken and GW Bruyn), pp. 343-367. North Holland, Amsterdam.

Sasanuma S and Monoi H (1975) The syndrome of Gogi (wordmeaning) aphasia: selective impairment of kanji processing.
Neurology, 25, 627-632.

Shoji H (1982) Clinical features of herpes simplex encephalitis. Neurological Medicine (Tokyo), 17, 95-97.

Shoji H, Teramoto H, Satowa H and Narita Y (1979) Partial Klüver-Bucy syndrome following probable herpes simplex encephalitis. Journal of Neurology, 221, 163-167.

Weisberg LA, Greenberg J and Stazio A (1988) Computed tomographic findings in acute viral encephalitis in adults with emphasis on herpes simplex encephalitis. Computerized Medical Imaging and Graphics, 12, 385-392.

Whitely RJ, Soong S, Linneman C, Liu C, Pazin G and Alford CA (1982) Herpes simplex encephalitis: clinical assessment. Journal of the American Medical Association, 247, 317-320. 


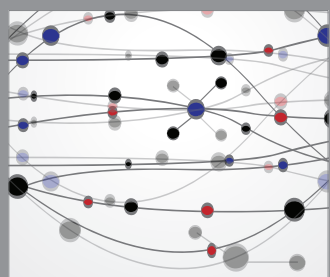

The Scientific World Journal
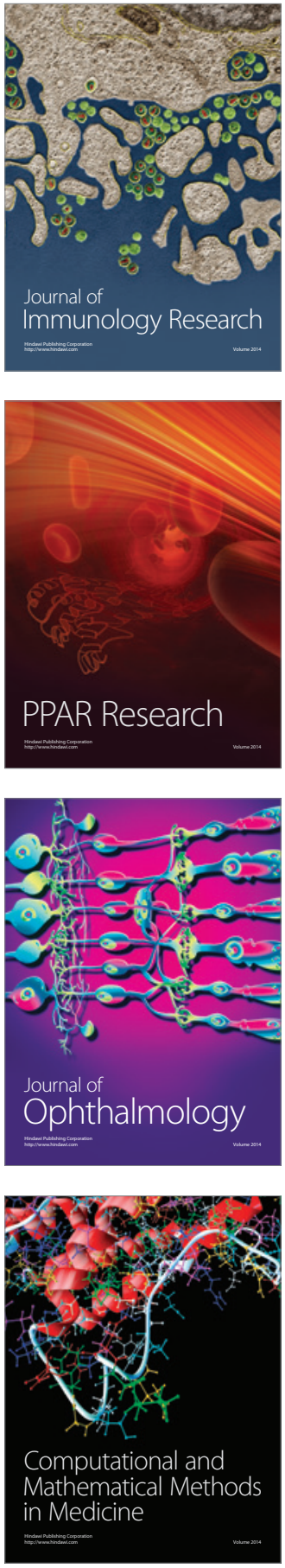

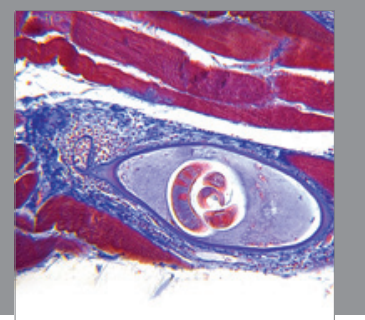

Gastroenterology

Research and Practice
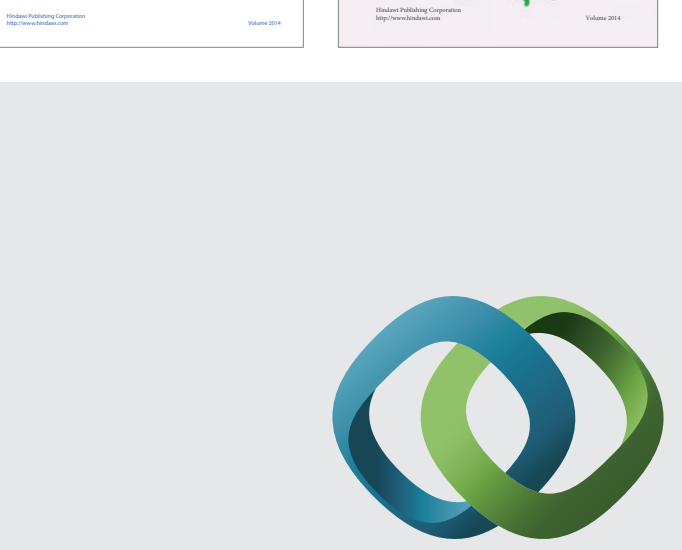

\section{Hindawi}

Submit your manuscripts at

http://www.hindawi.com
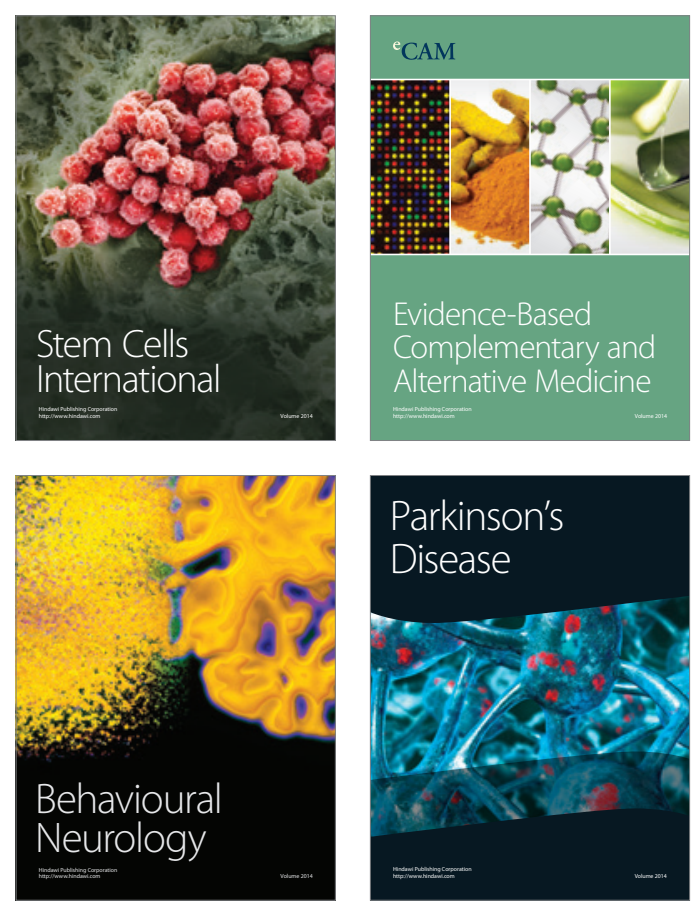

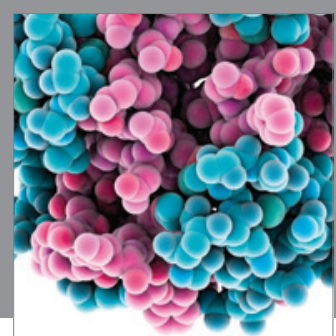

Journal of
Diabetes Research

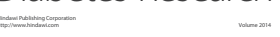

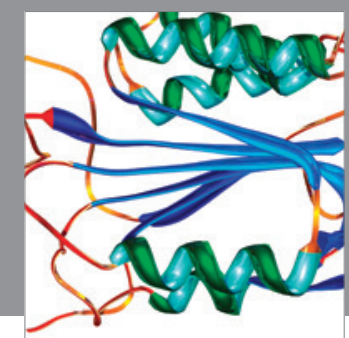

Disease Markers
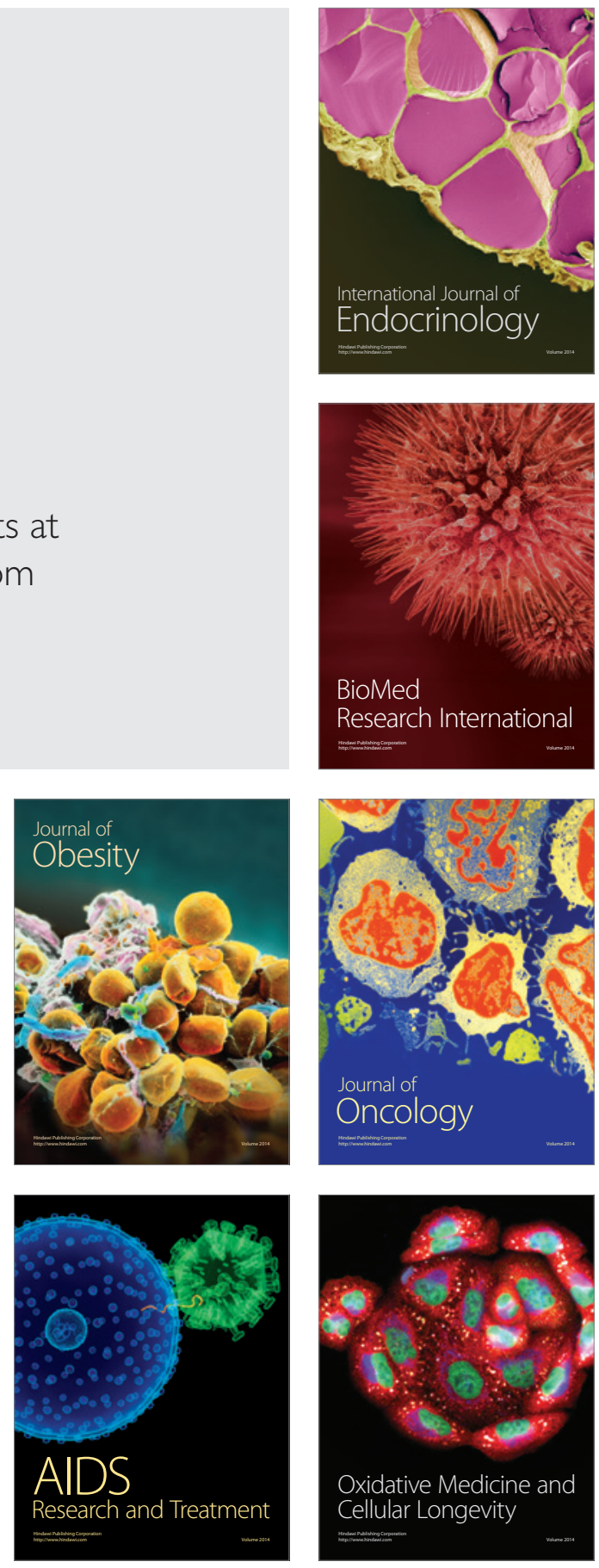